\title{
https://doi.org/10.46813/2021-134-065 \\ DEPENDENCE OF WAKEFIELD EXCITATION IN PLASMA BY NON-RESONANT SEQUENCE OF ELECTRON BUNCHES ON THEIR LENGTHS
}

\author{
D.S. Bondar ${ }^{1,2}$, A.P. Boychenko ${ }^{2}$, V.I. Maslov ${ }^{1,2}$, I.N. Onishchenko ${ }^{1}$, R.T. Ovsiannikov ${ }^{2}$ \\ ${ }^{1}$ National Science Center "Kharkov Institute of Physics and Technology”, Kharkiv, Ukraine; \\ ${ }^{2}$ V.N. Karazin Kharkiv National University, Kharkiv, Ukraine
}

The present paper describes the results of numerical simulation (using $2 \mathrm{~d} 3 \mathrm{v}$ code LCODE) of the regime, when the wakefield is excited at maximum growth rate in the plasma by a nonresonant sequence of relativistic electron bunches. As a result, the wakefield increases approximately in steps. The paper gives the parameters, at which this regime is achieved. It is shown that for smaller bunch radii, the amplitude of the excited wakefield is larger. At long lengths of the bunches, the amplitude of the wakefield is larger, in contrast to the excitation by the resonant sequence of bunches.

PACS: 29.17.+w; 41.75.Lx

\section{INTRODUCTION}

The PWFA has the ability to sustain an extremely high accelerating gradient [1-15]. For continuous operation of the accelerator, one needs to use a long sequence of drivers. But resonant wakefield excitation is difficult with the use of a long sequence of relativistic electron bunches because of the nonuniform and time-varying laboratory plasma. Here resonant is used to mean that the distance between the bunches in a bunch train is equal to the excited wavelength in the plasma. Then frequency of the bunches in a bunch train $\omega_{m}$ equals the electron plasma frequency $\omega_{m}=\omega_{p e}$. Also long sequence focusing and large transformer ratio obtaining [16 - 25] are difficult because of the nonuniform and time-varying laboratory plasma. Hence, the sequence of electron bunches can be nonresonant $\omega_{m} \neq \omega_{p e}$ for the laboratory plasma. Previously, the authors have developed the mechanism and carried out investigations [26, 27] on the excitation of the wakefield by a nonresonant sequence of electron bunches. The present paper describes the results of numerical simulation of wakefield excitation at maximum growth rate deep in the plasma under multi-bunched PWFA scheme in the nonresonant case for initially homogeneous plasma. In the plasma near the bunch injection boundary, the time chain of wakefield pulses (see Fig. 1) is formed, similarly to the case of any nonresonant excitation of oscillations. In Fig. 1 one can see that in the plasma near the bunch injection boundary the wakefield (shown in pink) is the periodical chain of wakefield pulses. The length of each wakefield pulse is equal to several excited wavelengths (Fig. 1). In the first half of each pulse the bunches get decelerated, and in the back half of each pulse the bunches get accelerated. Hence in first half of the pulse the wakefield amplitude increases and in the back half of the pulse the wakefield amplitude symmetrically decreases. Note that deep in the plasma this symmetry is not observed. In effect, a part of the bunches is defocused by the transverse wakefield. As a result, the bunches from decelerating phases are closer to the axis, and the bunches from accelerating phases are far from the axis. Hence, the bunches from the decelerating phases interact with the wakefield stronger in comparison with the bunches from the accelerating phases, because the wakefield amplitude decreases in the transverse direction. At some depth in the plasma the sequence of bunches, which interact strongly with the wakefield, becomes resonant due to defocusing of some bunches.

In this paper the authors present the numerical simulation data on the regime of nonresonant wakefield excitation at the maximum growth rate, which is realized at some depth in the plasma. The regime is characterized by the fact that at the front of the first half of the wakefield pulse the radius of the decelerating bunch is close to the initial one. The radii of bunches from the accelerating phases are much larger due to defocusing. Therefore, the bunches from the accelerating phases interact with the wakefield much weaker than the bunch at the front of the first half of the wakefield pulse, where wakefield increases quickly. As a consequence, the wakefield amplitude grows approximately in a stepwise manner. We mean that the wakefield amplitude rapidly increases over a short period of time, and then it changes only slightly over several plasma periods, to next process of wakefield amplitude growth (Fig. 5). This stepwise growth process is repeated many times (see Fig. 5). Investigations were performed by the 2.5D numerical simulation using the code LCODE [28].

We now analyse the wakefield excitation, considering the initial density of plasma to be lower than the resonant density $n_{0 e}<n_{\text {res }}\left(=\omega_{m}^{2} m\left(4 \pi e^{2}\right)^{-1}\right), \omega_{m}$ is the repetition frequency of bunches. Hence the repetition frequency $\omega_{m}$ of the bunches is a little higher than the electron plasma frequency $\omega_{m}>\omega_{p e}$. We use the parameters, for which the nonresonant wakefield is excited at the highest growth rate.

We also use the cylindrical coordinate system $(r, z)$. The time $\tau$ is normalized to $\omega_{p e}^{-1}$, all the distances - to $c \omega_{p e}^{-1}$, the density - to the unperturbed plasma electron density $n_{0 e}=10^{11} \mathrm{~cm}^{-3}$, the beam current $I_{b}-$ to $m c^{3} / e=17 \mathrm{kA}$, the fields - to $m c \omega_{p e} / e$, where $m$ is the electron mass, $e$ is the electron charge, $c$ is the 
speed of light, $\omega_{p e}$ is the plasma electron frequency. These normalisations are used also in the Figures.

We present the numerical simulation data on plasma wakefield excitation by a sequence of relativistic electron bunches, obtained with the $2.5 \mathrm{D}$ quasi-static code LCODE [28] that treats the plasma as a cold electron fluid, and the bunches as ensembles of macro-particles. The parameters are taken close to those of the plasma wakefield experiments, in which the electron beam represented by a regular sequence of electron bunches (each bunch being of energy $2.5 \mathrm{MeV}$, the rms radius $\sigma_{r}=0.5 \mathrm{~cm}$, and the rms angular spread $\sigma_{\theta}=0.05 \mathrm{mrad}$ ) excites the wakefield in the uniform plasma of density $n_{p}=10^{11} \mathrm{~cm}^{-3}$. The plasma wavelength equals $\lambda=10.6 \mathrm{~cm}$. The distribution of bunches is Gaussian in the longitudinal and transversal directions. The gamma factor of bunches is equal to $\gamma_{b}=5$. The plasma ions represent the immobile background.

Spatial step equals $0.1 c \omega_{p e}^{-1}$. Time step for plasma electrons equals $0.1 \omega_{p e}^{-1}$. Time step for beam electrons equals $0.1 \sqrt{\gamma_{b}} \omega_{p e}^{-1}$.

We present time dependences in selected points of observation.

The resonant and nonresonant regimes are fundamentally different. Only the $1^{\text {st }}$ bunch is focused in the resonant case while the remaining heads of the bunches are defocused, and the tails of the bunches are focused. In the nonresonant case under consideration, the repetition frequency of bunches is higher than the plasma frequency $\omega_{m}>\omega_{p e}$, and we observe that the bunches in the fronts of the wakefield pulses approach the zero radial wakefield (see Fig. 5), while the remaining bunches are strongly defocused.

In this paper, it is shown by numerical simulation that with an increase in a certain range of bunch lengths, the wakefield amplitude increases.

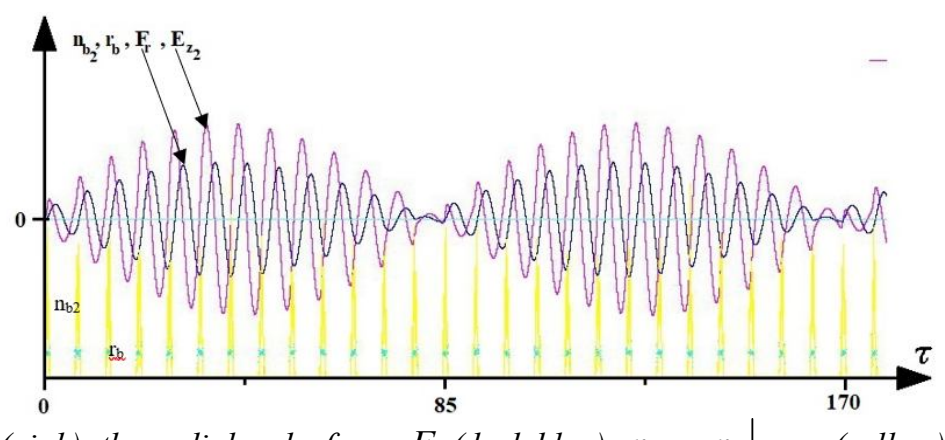

Fig. 1. $E_{z 2}=\left.E_{z}\right|_{r=r_{b 0}}$ (pink), the radial wake force $F_{r}$ (dark blue), $n_{b 2}=\left.n_{b}\right|_{r=r_{b 0}}$ (yellow) and the bunch radius $r_{b}$ (blue) as functions of the time for $\gamma_{b}=5 ;\left(n_{e}-n_{r e s}\right) n_{r e s}^{-1}=-0.15,2 \sigma_{z}=1.06 \mathrm{~cm}$, maximum initialelectron bunch current $I_{b}=1.05 \cdot 10^{-3}, z=5 \mathrm{~cm}, r_{b 0}$ is the initial radius of bunches

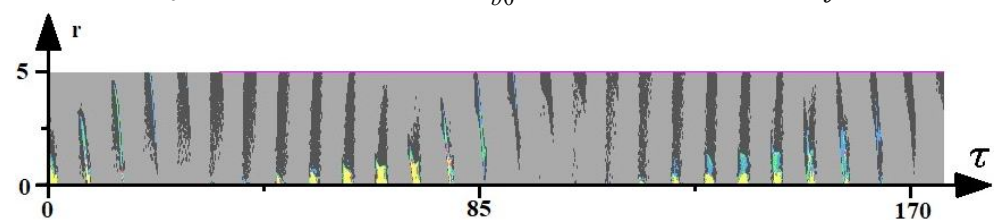

Fig. 2. Evolution (in time) of the beam density at $\gamma_{b}=5$; $\left(n_{e}-n_{\text {res }}\right) n_{\text {res }}^{-1}=-0.15,2 \sigma_{z}=1.7 \mathrm{~cm}$, maximum initialelectron bunch current $I_{b}=0.53 \cdot 10^{-3}, z=1.7 \mathrm{~m}$ 


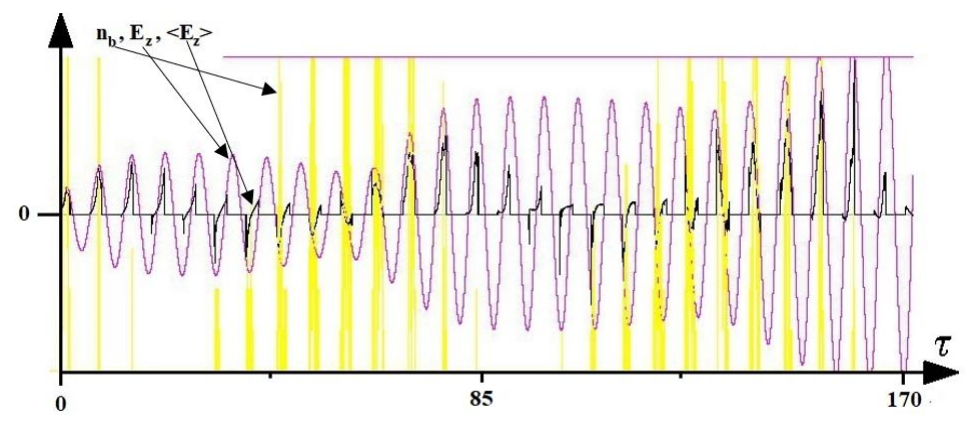

Fig. 3. The on-axis wakefield excitation $E_{z}$ (pink) by sequence of 28 bunches in the nonresonant case $\left(n_{e}-n_{r e s}\right) n_{r e s}^{-1}=-0.15,<E>=\int d r r E_{z} n_{b}\left(\int d r r n_{b}\right)$ (black) and density of bunches on the axis $n_{b}=\left.n_{b}\right|_{r=0}$ (yellow) as functions of the time $\tau$ for $\gamma_{b}=5,2 \sigma_{z}=1.7 \mathrm{~cm}$, maximum initialelectron bunch current $I_{b}=0.53 \cdot 10^{-3}$, $z=1.7 \mathrm{~m} \quad 2 \sigma_{z}=1.7 \mathrm{~cm}$

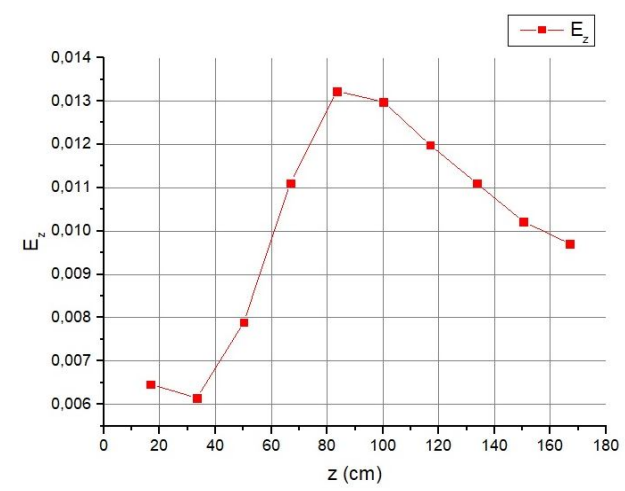

Fig. 4. The $E_{z}$ amplitude as a function of the coordinate along the plasma at $\gamma_{b}=5 ;\left(n_{e}-n_{\text {res }}\right) n_{r e s}^{-1}=-0.15$

The amplitude of the excited field is maximal at the depth equal to $z \geq 83 \mathrm{~cm}$ (Fig. 4). This value approximately equals 8 wavelengths.

At some depth in the plasma at the front of the first half of the wakefield pulse, the radius of the decelerating bunch is similar to the initial one. The radii of bunches from the accelerating phases are much larger due to defocusing. As a consequence, the bunches from the accelerating phases interact with the wakefield considerably weaker than the bunch at the front of the first half of the wakefield pulse. As a result, the wakefield amplitude grows approximately in steps. We mean that the amplitude of the wakefield rapidly increases over a short period of time, and for several plasma periods, to next process of wakefield amplitude growth, the ampli- tude changes only slightly (see Fig. 5). This stepwise growth process is repeated many times (see Fig. 5).

The optimal case (for the maximal growth rate of wakefield amplitude) may be represented by the case, where the accelerated bunches are defocused from the interaction area with the wakefield; and at the front of the first half of the wakefield pulse the radius of the decelerating bunch is close to the initial one. The decelerating bunch at the front of the first half of the wakefield pulse gets into the phase of small radial wake force, and for this reason the decelerating bunch has no time to be significantly defocused.

Now we consider the dependence of the wakefield amplitude on the length and radius of the bunches (Figs. $6,7)$. One can see that with an increase in a certain range of bunch length and decrease of bunch radius, the wakefield amplitude increases.

Now we demonstrate that, even with a large difference of the plasma electron density $n_{e}$ and the resonance one, the effective excitation of the wakefield occurs. In Fig. 8 one can see that for $\left(n_{e}-n_{\text {res }}\right) n_{\text {res }}^{-1}=-0.5$ growing beats of $E_{z}$ contain three bunches. The 1st bunch leads to an increase of the amplitude of $E_{z}$, the 2nd hardly exchanges energy with the wakefield, because it gets into $E_{z} \approx 0$. The 2 nd bunch simultaneously gets into the maximum $F_{r}$ and it is defocused. 3rd bunch takes energy from the wakefield less than the 1st bunch gave to the wakefield.

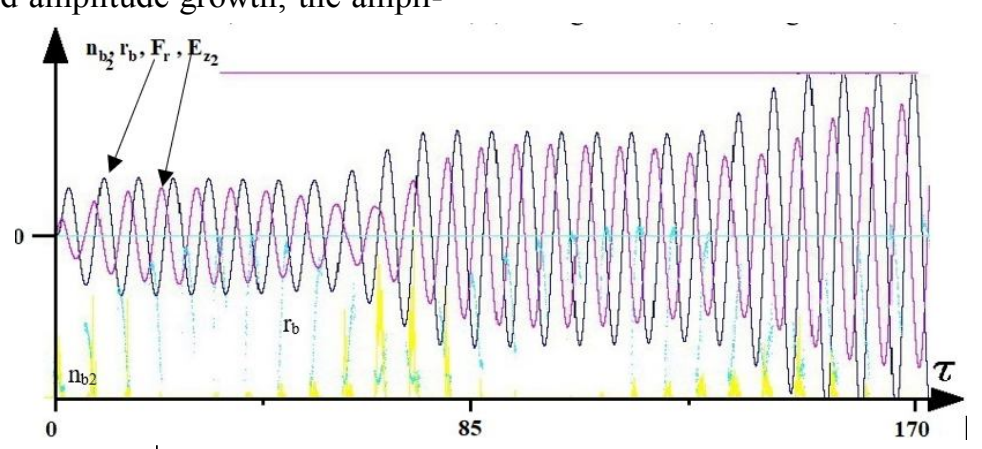

Fig. 5. Off-axis wakefield $E_{z 2}=\left.E_{z}\right|_{r=r_{0} 0}$ (pink) unlike on-axis wakefield in Figs. 3, 4, the radial wake force $F_{r}$ (dark blue), $n_{b 2}=\left.n_{b}\right|_{r=r_{b 0}}$ (yellow) and the bunch radius of $r_{b}$ (blue) as functions of the time for $\gamma_{b}=5$; $\left(n_{e}-n_{\text {res }}\right) n_{\text {res }}^{-1}=-0.15,2 \sigma_{z}=1.7 \mathrm{~cm}$, maximum initial electron bunch current $I_{b}=0.53 \times 10^{-3}, z=1.7 \mathrm{~m}$. The parameters are identical to Fig. 2-4. 


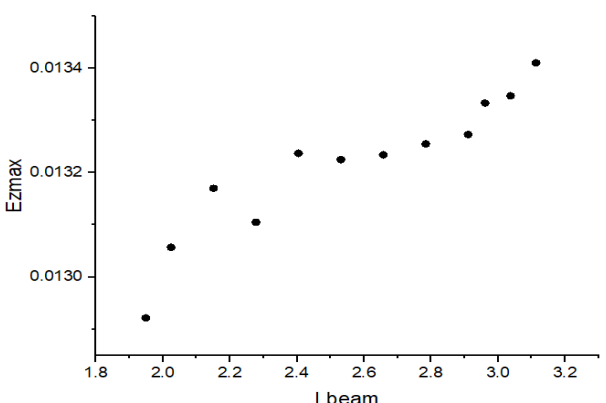

Fig. 6. The dependence of the wakefield amplitude

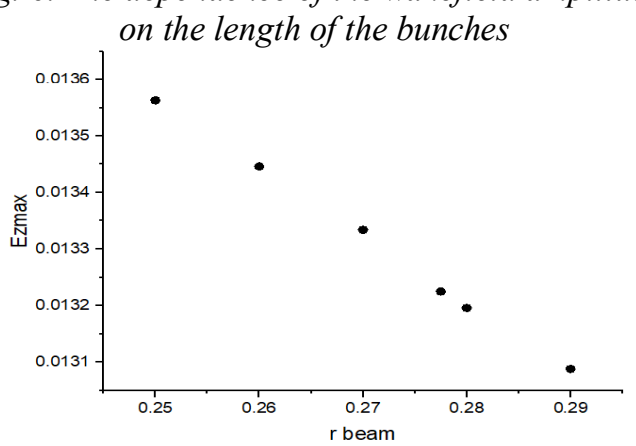

Fig. 7. The dependence of the wakefield amplitude on the radius of the bunches

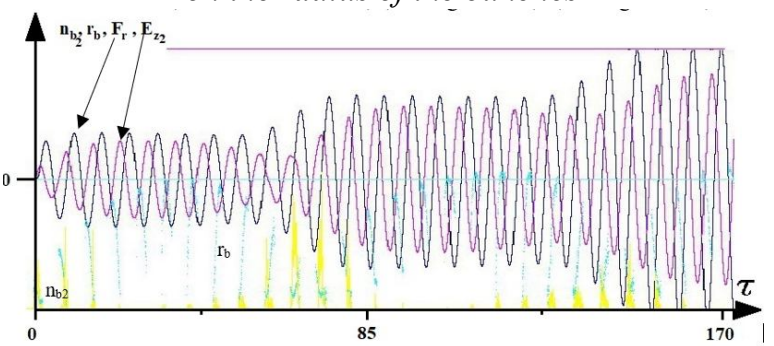

Fig. 8. Off-axis wakefield $E_{z 2}=\left.E_{z}\right|_{r=r_{b 0}}$ (pink), the radial wake force $F_{r}$ (dark blue), $n_{b 2}=\left.n_{b}\right|_{r=r_{b 0}}$ (yellow) and the bunch radius $r_{b}$ (blue) as functions of the time for $\gamma_{b}=5 ;\left(n_{e}-n_{\text {res }}\right) n_{\text {res }}^{-1}=-0.5$, maximum initial electron bunch current $I_{b}=1.05 \cdot 10^{-3}$

\section{CONCLUSIONS}

By numerical simulation the authors have demonstrated, that there are the electron bunch parameters at which the wakefield excitation by the non-resonant sequence of relativistic electron bunches gives rise to the regime, at which deep in the plasma the wakefield amplitude grows in steps at the highest growth rate. Also, it has been shown by numerical simulation that under this regime the non-resonant sequence loses some electrons due to defocusing and becomes resonant. The interaction of the wakefield with the electrons from the accelerating phases is found to be very low under this regime.

It is shown by numerical simulation that with an increase in a certain range of bunch length and decrease of bunch radius, the wakefield amplitude increases.

\section{ACKNOWLEDGEMENTS}

The study is supported by the National Research Foundation of Ukraine under the program "Leading and Young Scientists Research Support" (project \# 2020.02/0299).

\section{REFERENCES}

1. E. Esarey, S. Sprangle, J. Krall, A. Ting. Overview of Plasma-Based Accelerator Concepts // IEEE Trans. Plasma Sci. 1996, v. PS-24(2), p. 252-88.

2. A.V. Brantov, T.Zh. Esirkepov, M. Kando, H. Kotaki, V.Yu. Bychenkov, and S.V. Bulanov. Controlled electron injection into the wake wave using plasma density inhomogeneity // Phys. Plas. 2008, v. 15, p. 073111.

3. S. Lee, T. Katsouleas, R. Hemkel, and Mori. W2000 Simulations of a meter-long plasma wakefield accelerator // Phys. Rev. E. 2000, v. 61(6), p. 7014-21.

4. N. Kumar, A. Pukhov, and K. Lotov. Selfmodulation instability of a long proton bunch in plasmas // Phys. Rev. Lett. 2010, v. 104(25), p. 255003.

5. P. Walker. HORIZON 2020 EuPRAXIA Design Study // Proc. of IPAC2017 (Copenhagen: Denmark) TUOBB3.

6. P. Muggli et al. E-157: A plasma wakefield acceleration experiment // SLAC-PUB-8656. 2000, p. 1-6.

7. M.J. Hogan et al. E-157: A 1.4-m-long plasma wake field acceleration experiment using a $30 \mathrm{GeV}$ electron beam from the Stanford Linear Accelerator Center Linac // Phys. Plas. 2000, v. 7(5), p. 2241.

8. M. Hogan et al. Multi-GeV Energy Gain in a Plasma-Wakefield Accelerator // Phys. Rev. Lett. 2005, v. 95, p. 054802.

9. I. Blumenfeld et al. Energy doubling of $42 \mathrm{GeV}$ electrons in a metre-scale plasma wakefield accelerator // Nature. 2007, v. 445(7129), p. 741-44.

10. V.V. Tsakanov. On collinear wake field acceleration with high transformer ratio // NIMA. 1999, v. 432(23), p. 202-13.

11. A. Marocchino et al. High Brightness Electron Beams from Plasma-Based Acceleration // LINAC2018 (Beijing: China), p. 637.

12. M.C. Thompson, J. Rosenzweig, H. Band Suk. Plasma density transition trapping as a possible high-brightness electron beam source // Phys. Rev. Spec. Top. Accel. and Beams. 2004, v. 7, p. 011301.

13. K.V. Lotov, V.I. Maslov, I.N. Onishchenko, and E.N. Svistun. Simulation of plasma wakefield excitation by a sequence of electron bunches // Problems of Atomic Science and Technology. 2008, № 6, p. 114-16.

14. K.V. Lotov, V.I. Maslov, I.N. Onishchenko. Long sequence of relativistic electron bunches as a driver in wakefield method of charged particles acceleration in plasma // Problems of Atomic Science and Technology. 2010, № 6, p. 103-107.

15. K.V. Lotov, V.I. Maslov, I.N. Onishchenko, M.S. Vesnovskaya. 2d3v Numerical simulation of instability of cylindrical relativistic electron beam in plasma // Problems of Atomic Science and Technology. 2010, № 4, p. 12-16.

16. K.V. Lotov, V.I. Maslov, I.N. Onishchenko, and E.N. Svistun. Homogeneous Focusing of Electron Bunch Sequence by Plasma Wakefield // Problems of Atomic Science and Technology. 2012, № 31, p. 59-63. 
17. V.I. Maslov, I.N. Onishchenko, and I.P. Yarovaya. Plasma Wakefield Excitation, Possessing of Homogeneous Focusing of Electron Bunches // Problems of Atomic Science and Technology. 2013, № 1, p. 134-36.

18. V.I. Maslov, I.N. Onishchenko, and I.P. Yarovaya. Fields excited and providing a uniform focusing of short relativistic electron bunches in plasma // East European Journal of Physics. 2014, № 2, p. 92-95.

19. K.V. Lotov, V.I. Maslov, I.N. Onishchenko, and I.P. Yarovaya. Transformer Ratio at Interaction of Long Sequence of Electron Bunches with Plasma // Problems of Atomic Science and Technology. 2011, № 3, p. 87-91.

20. V.I. Maslov, I.N. Onishchenko, and I.P. Yarovaya. Transformer Ratio at Excitation of Nonlinear Wakefield in Plasma by Shaped Sequence of Electron Bunches with Linear Growth of Charge // Problems of Atomic Science and Technology. 2012, № 4, p. 128-30.

21. V.I. Maslov, I.N. Onishchenko, and I.P. Yarovaya. Wakefield Excitation in Plasma by Sequence of Shaped Electron Bunches // Problems of Atomic Science and Technology. 2012, № 6, p. 161-63.

22. I.P. Levchuk, V.I. Maslov, I.N. Onishchenko. Transformation ratio at wakefield excitation by linearly shaped sequence of short relativistic electron bunches in plasma // Problems of Atomic Science and Technology. 2015, № 6, p. 37-41.
23. V.I. Maslov, I.N. Onishchenko. Transformation ratio at wakefield excitation in dielectric resonator accelerator by shaped sequence of electron bunches with linear growth of current // Problems of Atomic Science and Technology. 2013, № 4, p. 69-72.

24. K.V. Lotov, V.I. Maslov, I.N. Onishchenko. Transformation ratio in wakefield method of acceleration for sequence of relativistic electron bunches // Problems of Atomic Science and Technology. 2010, № 4, p. 85-89.

25. V.I. Maslov, I.P. Levchuk, I.N. Onishchenko. Focusing of relativistic electron bunches by nonresonant wakefield excited in plasma // Problems of Atomic Science and Technology. 2010, № 4, p. 120123.

26. K.V. Lotov, V.I. Maslov, I.N. Onishchenko, and E.N. Svystun. 2.5D simulation of plasma wakefield excitation by a nonresonant chain of relativistic electron bunches // Problems of Atomic Science and Technology. 2010, № 2, p. 122-24.

27. K.V. Lotov, V.I. Maslov, I.N. Onishchenko, and I.P. Yarovaya. Mechanisms of Synchronization of Relativistic Electron Bunches at Wakefield Excitation in Plasma // Problems of Atomic Science and Technology. 2013, № 4, p. 73-76.

28. K.V. Lotov. Simulation of ultrarelativistic beam dynamics in plasma wake-field accelerator // Phys. Plasmas. 1998, v. 410(3), p. 785-91.

Article received 14.06.2021

\title{
ЗАВИСИМОСТЬ РЕЗОНАНСНОГО ВОЗБУЖДЕНИЯ КИЛЬВАТЕРНОГО ПОЛЯ В ПЛАЗМЕ НЕРЕЗОНАНСНОЙ ПОСЛЕДОВАТЕЛЬНОСТЬЮ ЭЛЕКТРОННЫХ СГУСТКОВ ОТ ИХ ДЛИН
}

\author{
Д.С. Бондарь, А.П. Бойченко, В.И. Маслов, И.Н. Онищенко, Р.Т. Овсянников
}

Описаны результаты численного моделирования (с использованием кода 2d3v LCODE) режима, когда кильватерное поле возбуждается с максимальной скоростью роста в плазме нерезонансной последовательностью релятивистских электронных сгустков. В результате кильватерное поле увеличивается примерно ступенчато. Приведены параметры, при которых достигается этот режим. Показано, что для меньших радиусов сгустка амплитуда возбужденного кильватерного поля больше. При больших длинах сгустков амплитуда кильватерного поля больше в отличие от режима возбуждения резонансной последовательностью сгустков.

\section{ЗАЛЕЖНІСТЬ РЕЗОНАНСНОГО ЗБУДЖЕННЯ КІЛЬВАТЕРНОГО ПОЛЯ В ПЛАЗМІ НЕРЕЗОНАНСНОЮ ПОСЛІДОВНІСТЮ ЕЛЕКТРОННИХ ЗГУСТКІВ ВІД ЇХ ДОВЖИН}

\author{
Д.С. Бондар, А.П. Бойченко, В.І. Маслов, І.М. Оніщенко, Р.Т. Овсянніков
}

Описані результати чисельного моделювання (з використанням коду 2d3v LCODE) режиму, коли кільватерне поле збуджується з максимальною швидкістю росту в плазмі нерезонансною послідовністю релятивістських електронних згустків. У результаті кільватерне поле збільшується приблизно поступово. Наведено параметри, при яких досягається цей режим. Показано, що для менших радіусів згустка амплітуда збудженого кільватерного поля більше. При великих довжинах згустків амплітуда кільватерного поля більше, на відміну від режиму збудження резонансною послідовністю згустків. 